\title{
MAPEAMENTO EM PLANTA DAS DUNAS FRONTAIS DO DELTA DO RIO PARAÍBA DO SUL (RJ) ENTRE 2005 E 2016
}

\author{
Beatriz Abreu Machado ${ }^{(a)}$, Gabriela da Silva Mello ${ }^{(b)}$, Jéssica Conceição da Silva ${ }^{(c)}$, Thaís \\ Baptista da Rocha ${ }^{(d)}$ \\ (a) Graduanda em Geografia pelo Instituto de Geografia, UERJ, bia_abreu23@ hotmail.com \\ (b) Graduanda em Geografia pelo Instituto de Geografia, UERJ, gabimel_gabi@ hotmail.com. \\ (c) Graduanda em Geografia pelo Instituto de Geografia, UERJ,silvajessica_19@ @otmail.com \\ (d) Prof. Dra. do Departamento de Geografia Física/ Instituto de Geociências, UFF,thaisitc5@ yahoo.com.br
}

\section{Eixo: DINÂMICA E GESTÃO DE ZONAS COSTEIRAS.}

\begin{abstract}
Resumo
O delta do Rio Paraíba do Sul (RJ) é uma área com expressiva ocorrência de dunas frontais, mais precisamente entre os distritos de Atafona e Grussaí. Desta forma, o objetivo principal deste trabalho é mapear e analisar a dinâmica das dunas frontais no Delta do rio Paraíba do Sul entre o período de 2005 e 2016 através de imagens de alta resolução. Em atafona, cujo litoral sofre erosão costeira, as dunas migraram em direção ao continente e sobre as edificações com uma taxa de até 3,9 m/ano, configurando uma evidente área de risco. Já em Grussaí, cujo litoral apresenta progradação, as dunas frontais avançaram em direção ao mar a uma taxa de cerca de 2,0 m/ano. Esse resultado está relacionado ao tipo de interação praia-duna frontal que é influenciado mais pelo comportamento da linha de costa na respectiva área, do que pelo tipo de morfodinâmica de praia.
\end{abstract}

Palavras chaves: Delta do rio Paraíba do Sul, dunas frontais, dinâmica de linha de costa.

\section{Introdução}

As dunas costeiras são feições geomorfológicas que se desenvolvem em praias arenosas e planícies costeiras, cujo aporte sedimentar é abundante e principalmente oriundo da zona submarina. Esses sedimentos chegam à parte subaérea da praia a partir da ação das ondas e as dunas costeiras podem se formar através dos ventos que sopram do mar para terra (Davidson-Arrnott,2010).

Dentre os diversos tipos de dunas costeiras, segundo Hesp (2002), as dunas frontais são consideradas acumulações paralelas a linhas de costa desenvolvidas no setor de pós-praia. Elas são feições eólicas que podem ocorrer em qualquer tipo de costa: praia, estuário, lagos e lagunas e em praticamente qualquer tipo de clima, desde tropical até polar. No geral, a morfologia das dunas frontais pode variar bastante, desde terraços relativamente planos até cristas convexas bem marcadas, podendo ser simétricas ou assimétricas. (Hesp, 2002). 
A partir de discussões recentes, se pode inferir que a evolução da morfologia das dunas frontais pode estar atrelada à dinâmica da linha de costa. Hesp e Walker (2013) descrevem dois principais cenários que apresentam essa relação. Em situações de progradação, os autores sugerem que a morfologia típica das dunas frontais apresente baixas cotas altimétricas e, portanto, uma largura considerável. Enquanto em situações de erosão/ retrogradação, as dunas tendem a apresentar cotas altimétricas mais elevadas em função de um processo denominado de scarpandfill (Hesp e Walker, 2013). Neste caso, uma parte da duna é erodida e, portanto disponibiliza sedimentos que serão remobilizados para o topo através de processos eólicos, promovendo a agradação desse cenário. Ainda segundo aos autores, dunas frontais em ambientes erosivos tendem a migrar ao continente, enquanto em ambientes progressivos, elas tendem a migrar em direção ao mar.

O flanco sul do delta do rio Paraíba do Sul é uma área expressiva de ocorrência das dunas frontais, mais precisamente entre os distritos de Atafona e Grussaí, no município de São João da Barra, de acordo com Fernandez et al (2009). Além disso, esse litoral frequentemente passa por realinhamentos da linha de costa em função da ocorrência de processos erosivos, próximo à Atafona, e de progradação, próximo à Grussaí. Por conta deste quadro, o objetivo principal deste trabalho é mapear e analisar a dinâmica das dunas frontais no Delta do rio Paraíba do Sul entre o período de 2005 e 2016 através de imagens de alta resolução. Esse trabalho tem a finalidade a auxiliar a análise da interação morfodinâmica entre praia e duna frontal na área mencionada.

\section{2. Área de estudo}

A área de estudo compreende uma faixa de praia de aproximadamente $10 \mathrm{Km}$ de extensão. Esta faixa está localizada entre as localidades de Atafona e Grussaí, no município de São João da Barra no litoral Norte Fluminense, mais especificamente ao sul da desembocadura do rio Paraíba do Sul.

Os ventos dominantes provêm, principalmente, do quadrante NE, pois estão associados à influência da Alta Pressão do Atlântico Sul. Este padrão mostra a dominância de ventos que incidem na direção do mar para a terra e que associado ao aporte continuo fluvial, propicia a incidência de dunas frontais ao longo da linha de costa (Santos, 2006). Segundo Souza (1988), durante o ano, a maior frequência da direção da incidência das ondas está associada a ventos locais dos quadrantes NE e E ocorrendo ainda ondas provenientes dos quadrantes $\mathrm{SE}$ e $\mathrm{S}$, associadas às frentes frias. $\mathrm{O}$ mesmo autor observou ainda que a altura média das ondas ao longo do ano é compreendida entre 1,6 e 2m, principalmente aquelas advindas do quadrante NE e E, enquanto as provenientes do quadrante SE e S, podem ser superiores a 3m. 


\section{Materiais e Métodos}

A fim de atingir os objetivos que se propõe o presente trabalho, fez-se inicialmente a definição do período temporal para a realização do mapeamento em planta da área de estudo, utilizando imagens de satélite e Ortofotos dos anos de 2005, 2010 e 2016. As Ortofotos do ano de 2005 foram obtidas tendo como fonte o Instituto Brasileiro de Geografia e Estatística (IBGE), e as imagens de satélite de 2010 e 2016, através do software Google Earth, a partir do acervo da Digital Globe. Em seguida, houve o processo de georreferenciamento das imagens de 2010 e 2016 no software ArcGis 10.1. As Ortofotos de 2005, já georreferenciadas, foram usadas como base para este procedimento.

Os pontos 6, 5 e 8 da rede de monitoramento do Laboratório de Geografia Física da Universidade Federal Fluminense foram os selecionados, pois apresentam de forma mais explicita o critério utilizado para o mapeamento, ou seja, o limite da linha de vegetação, que está associada aos processos de evolução e gênese das dunas frontais. Segundo Boak e Turner (2005), a linha de vegetação (Seawardvegetation) também representa um indicador de variação de linha de costa. O mapeamento das dunas frontais desses pontos nos períodos mencionados se deu através da criação de shapes e de vetorização no software ArcGis 10.1 tendo como base as Ortofotos e as imagens de satélite. Desta forma, para cada ponto, foram criados 3 shapes referentes a cada ano. A escala de mapeamento utilizada foi a de 1:3000. Para analisar a dinâmica das dunas frontais, houve a sobreposição dos shapes criados de cada ponto nas imagens de 2016 e a sobreposição do shape de 2016 nas Ortofotos de 2005 no ponto 6.

\section{Resultados e Discussões}

A Figura 1 mostra a dinâmica das dunas frontais, contendo a sobreposição dos shapes que as representam em 2005, 2010 e 2016 nos pontos de monitoramento escolhidos (P5, P6 e P8) da região entre Atafona e Grussaí. Na figura 1B, é possível observar as dunas frontais migrando em direção ao continente e, por consequência, avançando sobre edificações e vias públicas. Neste ponto, calcula-se uma taxa de aproximadamente 2,9m/ano de migração das dunas em direção ao continente. Na figura 1C, no ponto 6 de monitoramento, é possível observar as dunas migrando para o continente a partir de blowouts (cortes eólicos) que predominam na direção NE-SO, corroborando o modelo proposto por Santos (2006) acerca do regime de ventos. Já neste ponto, é possível observar, em alguns trechos, uma taxa em torno de 3,9m/ano de migração das dunas frontais em direção ao continente. Na figura 1D, no ponto 8 de monitoramento, notou-se o avanço das dunas em direção ao mar, apresentando, portanto, uma taxa de $2,1 \mathrm{~m} /$ ano de migração. 


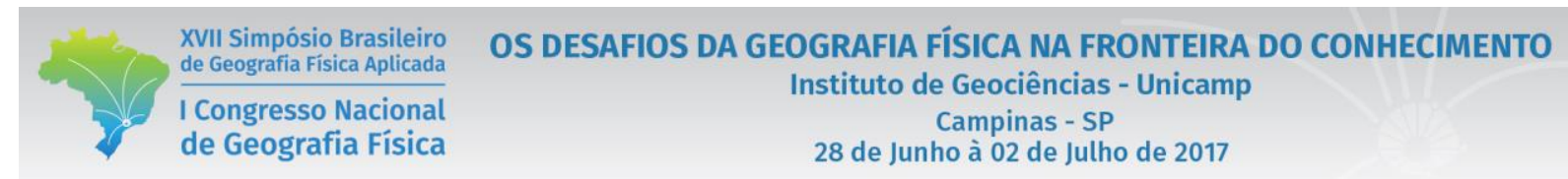

As taxas de migração das dunas obtidas na realização deste presente trabalho encontram-se próximas aos valores apresentados por Rocha et al (2016) acerca da variação de linha de costa. Segundo a autora, no perfil 6, após uma década de monitoramento, nota-se que este setor apresenta tendência de erosão costeira, visto que a base da duna frontal apresentou um recuo de aproximadamente 10 metros durante entre $2005 \mathrm{e}$ 2015. Já o perfil 8, por exemplo, apresenta comportamento de progradação, da ordem de aproximadamente 25 metros nos últimos dez anos, considerando o indicador morfológico da crista da berma, conforme apontado por Rocha et al (2016). Ainda segundo a autora, esse setor localizado no distrito de Grussaí, apresenta taxas de progradação de até 3,0m/ano, o que é semelhante aos 3,1m/ano já indicado por Santos (2016).

Assim, nota-se que os perfis 5 e 6 são representativos do setor de erosão costeira, conforme já indicado por Bastos (1997), Santos (2006), Rocha (2009) e Rocha et al (2016). Já o perfil 8 é representativo do setor de progradação de linha de costa, também apontado por esses autores. Desta forma, através dos materiais utilizados e do método proposto, foi possível mapear as dunas frontais e analisar sua dinâmica nos recortes espacial e temporal selecionados.
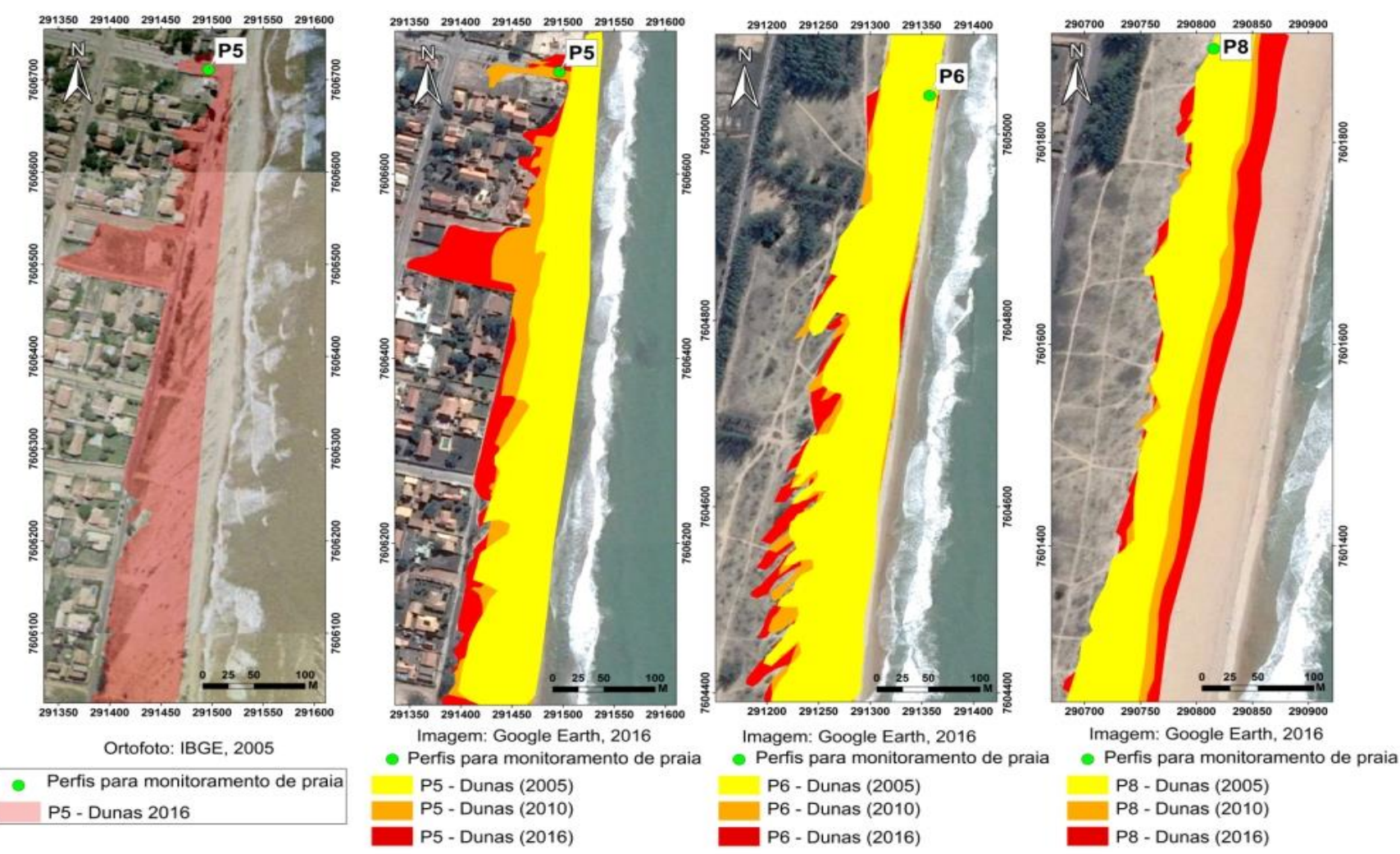

Figura 1 - (1A) Avanço das dunas frontais sob as edificações e vias públicas; (1B) Avanço progressivo destas dunas em direção à costa; (1C) Área de certa estabilidade; (1D) Progradação da linha de costa a partir da dinâmica das dunas frontais. 


\section{Considerações Finais}

Os resultados obtidos neste trabalho mostram uma relação direta entre a dinâmica das dunas frontais e a dinâmica da linha de costa. Nota-se que no ponto 5 e 6 do monitoramento, as dunas frontais migram em direção ao continente, associado ao processo erosivo da linha de costa, conforme apontado por Rocha et al (2016). Por fim, o ponto 8 infere o avanço das dunas frontais em direção ao mar associado à progradação da linha de costa, corroborando o modelo proposto por Hesp e Walker (2013). Esse trabalho também sugere que a análise e o mapeamento das dunas frontais a partir do limite da vegetação funciona como um indicador de linha de costa. Tendo em vista as mudanças climáticas e as possíveis elevações do nível do mar, as dunas frontais se colocam como excelentes indicares de comportamento de linha de costa e portando o estudo da mesma se torna importante e relevante para a sociedade.

\section{Bibliografia}

BASTOS, A.C. Análise morfodinâmica e caracterização dos processos erosivos ao longo do litoral norte fluminense, entre Cabiúnas e Atafona. Niterói, 1997. 133 f. Dissertação (Mestrado em Geologia e Geofísica Marinha), Instituto de Geociências, Universidade Federal Fluminense, Niterói, 1997.

BOAK, E.H., TURNER, I.L. (2005) Shoreline Definition and Detection: A Review. Journal of Coastal Research: Volume 21, Issue 4: pp. $688-703$.

DAVIDSON-ARNOTT, R. An Introduction to Coastal Processes and Geomorphology. Cambridge University Press. 2010.

DOMINGUEZ, J.M.L.; MARTIN, L.; BITTENCOURT, A.C.S.P. 1981. Esquema evolutivo da sedimentação Quaternária nas feições deltaicas dos rios São Francisco (SE/AL), Jequitinhonha (BA), doce (ES) e Paraíba do Sul (RJ). Revista Brasileira de Geociências, 11(4), p.227-237.

FERNANDEZ, G.B., PEREIRA, T.G, \& ROCHA, T.B. 2008b. Modelo morfológico da origem e evolução das dunas na foz do rio Paraíba do Sul, RJ. Anais do VIII Simpósio Nacional de Geomorfologia/SINAGEO. Belo Horizonte, MG. Brasil.

HESP, P.A. e WALKER, I.J. Coastal Dunes. In: John F. Shroder (ed.) Treatise on Geomorphology, Volume 11, pp. 328-355. San Diego: Academic Press. 2013

HESP, P. Foredunes and blowouts: initiation, geomorphology and dynamics. Geomorphology, v.48, 245 - 268. 2002.

ROCHA, T.B.; MACHADO, B. A.; SILVA, J. C.; PEREIRA, T.G; FERNANDEZ, G.B. Interação entre praia e duna frontal no delta do rio Paraíba do Sul (RJ) a partir de uma década de monitoramento. In: XI SINAGEO, 2016, Maringá - PR. XI SINAGEO, 2016.

ROCHA, T.B .2009. Morfodinâmica Costeira e Gestão de Orla marítima em costa sob influência fluvial: Borda meridional do atual delta do Rio Paraíba do Sul, RJ. Dissertação de Mestrado. Pós graduação em Geografia- Universidade Federal Fluminense- UFF, Niterói, RJ.141p.

SANTOS, R.A. 2006. Processos de Erosão e Progradação entre as praias de Atafona e Grussaí - RJ. Monografia de Graduação, Curso de Geografia - Universidade Federal Fluminense - UFF. Niterói, RJ. 36p.

SHORT, A.D., HESP, P.A., 1982. Wave, beach and dune interactions in southeastern Australia. Marine Geology 48, $259-284$. 